\title{
Perspectives
}

\section{Shared decision making and non-directiveness in genetic counselling}

\author{
Glyn Elwyn, Jonathon Gray, Angus Clarke
}

The term "genetic counselling" (GC) covers many different activities, but at its core it is a process of communication. ${ }^{1}$ It can refer to the diagnostic assessment of a child with multiple developmental problems. It can describe the facilitation of a decision making process in relation to predictive genetic testing for a late onset disorder. It can relate to a decision about prenatal diagnosis or the termination of a pregnancy at risk of a serious inherited disease. Topics discussed within GC can include plans for the continuing medical management of a person at risk of complications of a genetic disease, and can encompass whether or how to broach the topic of genetic disease with other members of the extended family.

The nature of the clinic discussion of these different elements of GC will vary greatly, and any one consultation is likely to entail a discussion of only one or a few from the full range of possible topics.

Clinical geneticists, in contrast to most other medical practitioners, are said to espouse a "non-directive" method of "counselling" clients. ${ }^{23}$ This is generally taken to mean that clinical geneticists are trying to help their clients arrive at the best decisions from personal perspectives and are not guiding them towards any particular decision (for example, to test or not to test, to terminate a pregnancy or to continue it). Whether non-directiveness (ND) is attainable, however, remains unclear and contested.

There are good reasons why clinical geneticists and genetic counsellors might wish to claim that their work is non-directive. ${ }^{4}$ Such a stance is in keeping with the contemporary dominance of autonomy over the other recognised principles of medical ethics. ${ }^{5}$ It protects the profession from an easy confusion with, and moral contamination from, the eugenics movement, and this will be useful to genetic counsellors both in public debate and internally within themselves. It protects the counsellors from over-involvement with clients and perhaps also from litigation. ${ }^{6}$ The definition of ND that we have presented so far, however, is of only limited use. It does not amount to an operational definition that enables us to recognise ND in practice, and it does not enable us to tackle the question of what guidance of clients by counsellors might be appropriate.

Non-directiveness may be difficult or impossible to achieve for many reasons. There may be structural (health service organisation) or social factors that promote uptake of a screening test that cannot be adequately neutralised by the behaviour of the counsellor within the consultation. ${ }^{4}$ There may be good clinical reasons for the clinician to recommend surveillance for complications of the family's genetic disorder, ${ }^{3}$ as in Marfan syndrome or some family cancer disorders. The information given to clients may be tailored to their specific situation and their understanding and value system, rather than a predetermined set of facts being transmitted ${ }^{7}$; this selection and framing of information will influence the decisions made by clients..$^{8-10}$ Indeed, there is an inherent difficulty in separating the giving of information, which is acceptable within ND, from the giving of advice, which is not. ${ }^{11}$ There may also be valid ethical reasons for a clinician or counsellor to recommend a specific course of action to clients, for example, for them to transmit information about their genetic condition to other members of their family. ${ }^{12}$

\section{Directiveness and non-directiveness}

Kessler ${ }^{13}$ has suggested that all genetic counselling entails influencing clients or attempting to do so, but that directive counselling aims to influence their behaviour in a specific way, whereas non-directive counselling attempts to influence their thinking and the process by which they arrive at decisions. Wolff and Jung ${ }^{14}$ have developed this theme, pointing out that the goal of Rogerian ND in psychotherapeutic counselling is the promotion of client maturation, but that in GC the goal of ND has, in practice, often amounted to a restriction of the scope of professional responsibility. They suggested that the term ND should no longer be used in the context of GC and argued that the responsibilities of the counsellors need to be better defined. Shiloh ${ }^{15}$ has written that genetic counsellors (should be) "helping clients reach a decision wisely rather than reach a wise decision". How would we recognise and distinguish between the counselling that is non-directive (that is, a "wise" process) and that which is directive (and, perhaps, "unwise")?

One approach has been to use a decontextualised definition of ND, no direction provided vis a vis the action to be taken, and measured from the viewpoints of both counsellor and counsellee respectively, as in the work of 
Michie et al. ${ }^{16}$ Unfortunately, this approach is unable to acknowledge or respond to the clinical context and is therefore unable to contribute to discussions of, with, or among practitioners in relation to their work. ${ }^{6}$ Neutrality in GC has been assessed by van Zuuren ${ }^{17}$ using a Grounded Theory approach (based on a qualitative analysis of data from actual practice), and this work, as does that of Michie et $a l,{ }^{16}$ shows frequent deviations from $\mathrm{ND}$, as emerged from interviews with counsellors. ${ }^{3} 10$ This approach has led to recommendations for the training and practice of genetic counsellors. Kessler, ${ }^{13}$ rather than agreeing to avoid the term "non- directiveness", has developed his approach and proposed a definition that can apply to GC. He accepts that the concept of ND cannot simply be lifted from Rogerian psychotherapy, because the counsellor in GC cannot delegate the entire responsibility for the counselling agenda to the client; he proposes a modified definition for the genetic context: "Non-directiveness describes procedures aimed at promoting the autonomy and selfdirectedness of the client". ${ }^{18}$ Although this modifies the concept of "not directing" clients, this definition allows us to acknowledge that informative, prescriptive, or confrontational interventions made by the counsellor can sometimes be non-directive, ${ }^{19}$ even if the client has not previously sought such an intervention from the counsellor. For example, the counsellor may provide some information to the client, suggest one or two possible courses of action, or ask the client to consider the consequences of their decision for other members of their family. The operationalisation of Kessler's definition in research studies may still be difficult, but will be possible within analytic frameworks that attend to context and to the full range of communicative processes within GC.

\section{When might non-directiveness be inadequate?}

We have seen, above, that ND remains central to professional self understandings within GC, but there are some areas where counsellors clearly find the ND approach difficult to maintain. This may be because their communication and counselling skills are insufficient, ${ }^{18}$ but there are two contexts in which ND may be inappropriate as a framework to guide counsellor practice.

There are particular circumstances when a counsellor, especially if she/he is also a clinician, may wish frankly to recommend a course of action to the client. This may happen when the counsellor considers it to be in the client's best interests, as understood in a narrow, conventional medical sense, to accept some treatment or investigation: we can call this a clinical recommendation. ND may also appear inadequate when the counsellor recommends a course of action to the client for ethical reasons, as when it would be in the interests of other family members for the client to disclose information about him/herself because they may find it helpful to know about their risk of developing a genetic disorder or of having a child affected by a genetic disorder: we can call this an ethical recommendation. We suggest that shared decision making (SDM) can prove helpful as a way of incorporating such considerations into our understanding of GC and to help judge the appropriateness of such interventions.

\section{Shared decision making (SDM) and clinical recommendations}

Shared decision making provides an approach that is complementary to the "non-directive" approach, and it provides a framework that is open to evaluation. ${ }^{20-23}$ Although there is little in the way of empirical work using the SDM approach, the model is actively debated both by clinicians ${ }^{24}$ and by health economists ${ }^{25}$ as one that can provide many advantages as clinicians balance the tensions between evidence based guidance and the need to respect patient choice. Geneticists also face the challenge of making complex information about risk and uncertainty accessible to patients and we feel that the SDM framework would prove helpful. The issue of evaluation will be especially important when clinical outcomes are being influenced by the decisions made. SDM can be helpful when the counsellor seeks the opportunity to make a clinical recommendation to the client and provides guidance as to how this degree of "directiveness" could be negotiated.

In SDM, the clinician/counsellor and the client share information on the basis of which a decision is to be made. They then discuss their views and come to an agreed decision for which they share the responsibility. SDM should not be regarded as a prescriptive set of rules but the principles allow ND to flourish where it is relevant and also allow the clinician to contribute his professional opinion (a valid biomedical perspective) into the decision making process, without denying the critical importance of the patient's wider value systems. The characteristics of SDM are presented in table 1, with the suggested competencies and stages listed in table 2. As SDM receives increasing interest within the field of "patient centred" and "evidence based" medicine, ${ }^{26}{ }^{27}$ its potential in medical genetics should be considered.

In the realm of clinical genetics, decisions must often be made on the basis of probabilities rather than certainties, and with incomplete or biased information about likely outcomes uncertainty is the norm. ${ }^{28}$ In order to arrive at important decisions, facts (or uncertainties) need to be integrated in the mind of the client along with strong emotions, core personal values, and difficult judgements about the likely responses of other people. ${ }^{29}$ These uncertainties and complexities do not exclude the SDM process, but such issues have to be

Table 1 Principles of shared decision making ${ }^{22}$

- Shared decision making involves at least two (often many more) participants - as a minimum, the doctor and the patient

- Both parties take steps to participate in the process of decision making

- Information sharing is a prerequisite to sharing of the decision making

- A decision is made and both parties agree to it 
Table 2 Stages and competencies of involving patients in health care decisions ${ }^{40}$

(1) Implicit or explicit involvement of patients in decision making process

(2) Explore ideas, fears, and expectations of the problem and possible treatments

(3) Portrayal of options

(4) Identify preferred format and provide tailor made information

(5) Checking process: understanding of information and reactions (eg, ideas, fears, and expectations of possible options)

(6) Acceptance of process and decision making role preference

(7) Make, discuss, or defer decisions

(8) Arrange follow up

made explicit and recognised as imponderables by both professional and client. Such processes may be needed in counselling for decisions about predictive testing or reproduction. However, where the principal issues relate to the health of the person, then there is no reason why the counsellor should not contribute his or her views about a course of action to the client if there is good evidence that it will be to the client's direct, medical benefit, as in any other branch of medicine, provided there is respect for the ultimate autonomy of the person concerned. There is also a case for adopting SDM in wider areas of GC when the competence of the client is limited and the counsellor is able to take a view on their "best interests" in consultation with other involved parties, such as social workers or the courts, but this area is especially complex and requires a separate treatment.

The respect for client autonomy that underlies professional enthusiasm for SDM in primary health care is also well developed in GC, making SDM a natural approach to the negotiation of management decisions in clinical genetics. SDM may also be applicable to negotiations about diagnostic pathways; when investigations are being planned to establish a diagnosis then the likely benefits to emerge may be weighed jointly by clinician and patient along with the inconvenience, anxiety, pain, and other consequences of the diagnostic process.

For SDM to occur, there needs to be a two way exchange, not only of information ${ }^{30}$ but also of preferences about plans for management or intervention. A set of "competencies" relevant to SDM has been described, skills that facilitate the shared decision making process within consultations (table 2). It is assumed that the agenda matching and problem solving phases of the consultation have been successfully completed. It will be interesting for genetic counsellors to examine their practice and look for evidence of SDM in operation. It may be that GC has evolved towards this approach in practice, under the guise of non-directiveness, when a rigid approach to ND has been regarded as unhelpful. Primary care has been evolving towards SDM from the different tradition of beneficient paternalism.

There are nevertheless a number of questions that can be raised about any attempt to adopt SDM. Is the process of decision making about management issues helped by the counsellor being prepared to state his/her view? Will the client in practice be persuaded to agree with the counsellor because she/he cannot marshall good enough debating points against the professional? Is it possible for the professionals to lay their cards on the table and still respect the client's views and values? Will the client "make" a decision at all, in the rational sense, or will she/he simply recognise the decision made by his/her own intuition? Cognitive psychologists note that we often simplify complex information, and use heuristic methods (rules of thumb) to arrive at decisions where probabilities and preferences about varying outcomes have to be juggled.

Furthermore, do patients want to share decisions? There are many publications that evaluate patient preferences for seeking information and for involvement in SDM. ${ }^{31}{ }^{32}$ Although this work shows that increasing age and decreasing levels of education predict a more "dependent" attitude, there is no rule or formula to determine individual patient preference for involvement in decision making, and it needs to be determined within each consultation. Assumptions should not be made about the degree of involvement wanted by clients. ${ }^{31}$ It is especially important that clients/patients do not feel abandoned to make important decisions without sufficient support, when counsellors, for example, withdraw from any involvement. ${ }^{33}{ }^{34}$ In one study, most women making a decision about predictive testing for breast cancer wanted to hear providers' recommendations about testing. ${ }^{35}$ Women still wanted to make their own decision, either choosing to follow the provider's recommendation or choosing to veto it. Such issues provide no reason for not adopting SDM in those areas of GC practice where $\mathrm{ND}$ is inadequate, however, and can be addressed in the future by systematic studies of the GC process.

\section{Shared decision making and ethical recommendations}

Another aspect of GC in which SDM might be considered appropriate relates to the implications of genetic information about one person for other family members. If one person is found to have a late onset disorder, whether untreatable like Huntington's disease (HD), or where interventions can be of great benefit, as with familial adenomatous polyposis coli (FAP), it may be helpful for other family members to be told. This gives them the opportunity to plan their lives, to make informed decisions about reproduction, and to seek surveillance for early signs of a complication for which medical intervention can be effective.

If an affected subject, or at least someone carrying the relevant mutation, is reluctant to let other family members know about the possible implications, then how should the counsellor respond? Of course, he/she can ask the client to think through the implications for other family members and discuss the sometimes bitter feelings that can arise when such information has been deliberately withheld. Usually, the combination of time and the 
opportunity to ponder on such possibilities will lead the client to conform to professional expectations.

It is clear that genetic counsellors are far from being non-directive in such matters. We are not even pretending. In addition, semi-official reports such as that of the Nuffield Council on Bioethics $^{12}$ recommend that counsellors attempt to persuade those who are reluctant to pass on to other family members potentially important genetic information to do so.

We will not address here the topic of what a counsellor should do if their client persists in refusing to transmit information to other members of their family. This is addressed elsewhere. ${ }^{36} 37$ But how should we view the attempt to persuade the client ? Does it amount to "SDM"? The answer is that it does not count as SDM because there has been no agreement between client and counsellor, which is an essential element of SDM. The failure of SDM in a consultation where conflict occurs between a doctor and a patient about the need to use antibiotics in for a viral upper respiratory infection underpins this conclusion. ${ }^{38}{ }^{39}$ Neither ND nor SDM provides an adequate account of such GC practices in which the professional's ethical concerns may lead to an unresolved difference of judgement between the counsellor and the client.

\section{Conclusions}

The concept of shared decision making may well be applicable to some of the aspects of GC in which ND is not appropriate, especially where the client is at risk from a genetic condition and is likely to benefit from specific medical management; it may also be helpful in negotiations about the organisation of complex diagnostic investigations. The concept of nondirectiveness, as developed by Kessler ${ }^{13}$ and others, provides an appropriate framework for understanding many aspects of GC, especially in relation to reproductive decisions and predictive genetic testing, but we feel that SDM provides an additional and useful framework for the complex interactions that inevitably occur in genetic consultations. Neither ND nor SDM, however, is applicable to contexts of conflict in which the counsellor's professional ethical approach leads them to (attempt to) persuade the client to disclose personal genetic information to other family members against their inclination. Detailed studies of the GC process will be able to assess the extent to which the ND and SDM paradigms are applied in practice within GC, the applicability of other models of GC practice, and the scope for improving practice through the improved training of professionals.

Jonathon Gray is supported by Tenovus.

1 Fraser FC. Genetic counselling. Am $\mathcal{f}$ Hum Genet 1974;26:636-59.

2 Wertz DC, Fletcher JC. Attitudes of genetic counsellors: a multinational survey. Am 7 Hum Genet 1988;42:592-600.

3 Bartels DM, LeRoy BS, McCarthy P, Caplan AL. Nondirectiveness in genetic counselling: a survey of practiNondirectiveness in genetic counselling: a
tioners. Am f Med Genet 1997;72:172-9.

4 Clarke A. Is non-directive counselling possible? Lance 1991;335:1145-7. 5 Schneider CE. The practice of autonomy: patients, doctors, and
medical decisions. New York: Oxford University Press, 1998. 6 Clarke A. The process of genetic counselling. In: Harper PS, Clarke A, eds. Genetics, society and clinical practice. Oxford: Bios Scientific Publishers, 1997.

7 Brunger F, Lippman A. Resistance and adherence to the norms of genetic counselling. F Genet Couns 1995;4:15167.

8 Tversky A, Kahneman D. The framing of decisions and the psychology of choice. Science 1981;211:453-8.

9 Shiloh S, Sagi M. Effect of framing on the perception of genetic recurrence risks. Am f Med Genet 1989;33:130-5.

10 Burke BM, Kolker A. Directiveness in prenatal genetic counselling. Women and Health 1994;22:31-53.

11 Silverman D. Discourses of counselling. London: Sage, 1997.

2 Nuffield Council on Bioethics. Genetic screening - ethical issues. London: Nuffield Council on Bioethics, 1993.

13 Kessler S. Psychological aspects of genetic counselling. VII. Thoughts on directiveness. F Genet Couns 1992;1:164-71.

14 Wolff G, Jung C. Non-directiveness and genetic counselling. F Genet Couns 1995;4:2-25.

15 Shiloh S. Decision-making in the context of genetic risk. In: Marteau TM, Richards MPM, eds. The troubled helix. The social and psychological implications of the new human genetics. Chapter 3. Cambridge: Cambridge University Press, 1996.

16 Michie S, Bron F, Bobrow M, Marteau TM. Nondirectiveness in genetic counselling: an empirical study. $\mathrm{Am}$ f Hum Genet 1997;60:40-7.

17 van Zuuren FJ. The standard of neutrality during genetic counselling: an empirical investigation. Patient Educ Couns 1997;32:69-79.

18 Kessler S. Psychological aspects of genetic counseling. XI. Nondirectiveness revisited. Am f Med Genet 1997;72:16471 .

19 Heron J. Six category intervention analysis. Human potential research project. 3rd ed. Guildford: University of Surrey, 1989.

20 Elwyn G, Edwards A, Kinnersley P. Shared decisionmaking: the neglected second half of the consultation. $B r F$ Gen Pract 1999;49:477-82.

21 Coulter A. Partnerships with patients: the pros and cons of shared clinical decision-making. F Health Serv Res Policy 1997;2:112-21.

22 Charles C, Gafni A, Whelan T. Shared decision-making in the medical encounter: what does it mean? (Or it takes at least two to tango). Soc Sci Med 1997;44:681-92.

23 Entwistle VA, Sheldon TA, Sowden IS, Watt IS. Evidenceinformed patient choice: issues of involving patients in Care (in press).

24 Elwyn G, Edwards A, Gwyn R, Grol R. Towards a feasible model for shared decision-making: a focus group study with general practice registrars. BMF 1999;319:753-7.

25 Gafni A, Charles C, Whelan T. The physician-patient encounter: the physician as a perfect agent for the patient versus the informed decision-making model. Soc Sci Med 1998;47:347-54.

26 Stewart M, Brown JB, Weston WW , McWinney IR, McWilliam CL, Freeman TR. Patient centred medicine: transforming the clinical method. Thousand Oaks, CA: Sage Publications, 1995.

27 Muir Gray JA. Evidence-based healthcare. New York: Churchill Livingstone, 1996

28 van Zuuren FJ, van Schie ECM, van Baaren NK. Uncertainty in the information provided during genetic counseling. Patient Educ Couns 1997;32:129-39.

29 Redelmeier DA, Rozin P, Kahneman D. Understanding patients' decisions. Cognitive and emotional perspectives. FAMA 1993;270:72-6.

30 Ong LML, de Haes JCJM, Hoos AM, Lammes FB. Doctorpatient communication: a review of the literature. Soc $S c i$ patient communication:

31 Guadagnoli E, Ward P. Patient participation in decisionmaking. Soc Sci Med 1998;47:329-39.

32 Deber RB, Kraetschmer N, Irvine J. What role do patients wish to play in treatment decision making? Arch Intern Med 1996;156:1414-20.

33 Quill TE, Cassel CK. Nonabandonment: a central obligation for physicians. Ann Intern Med 1995;122:368-74.

34 Quill TE, Brody H. Physician recommendations and patient autonomy: finding a balance between physician power and patient choice. Ann Intern Med 1996;125:763-9.

35 Holtzman NA, Bernhardt BA, Doksum T, Helzlsouer KA, Geller G. Education about BRCA1 testing decreases women's interest in being tested. Am 7 Hum Genet Suppl 1996; 59:A56.

36 Clarke A. Genetic screening: a response to Nuffield. Bull Med Ethics 1994:940:13-21.

37 Clarke A. Challenges to genetic privacy: the control of personal genetic information. In: Harper PS, Clarke A, eds. Genetics, society and clinical practice. Chapter 11. Oxford: Bios Scientific Publishers, 1997.

38 Elwyn G, Gwyn R, Edwards AGK, Grol R. Is a 'shared decision' feasible in a consultation for a viral upper respiratory tract infection: assessing the influence of patient expectations for antibiotics using discourse analysis. Health Expect 1999;2:105-17.

39 Gwyn R, Elwyn G. When is a shared decision not (quite) a shared decision? Negotiating preferences in a general practice encounter. Soc Sci Med 1999;49:437-47.

40 Elwyn G, Edwards A, Kinnersley P, Grol R. Shared decisionmaking: defining the competencies of involving patients in healthcare choices. Cardiff: Department of General Practice, University of Wales College of Medicine, 1999. 